\title{
Soil moisture derivation using triangle method in the lighvan watershed, north western Iran
}

\author{
M. Rahmati*, M.M. Oskouei², M.R. Neyshabouri ${ }^{3}$, J.P. Walker ${ }^{4}$, A. Fakherifard ${ }^{5}$, A. \\ Ahmadi $^{3}$, S.B. Mousavi ${ }^{1}$ \\ ${ }^{1}$ University of Maragheh, Faculty of Agriculture, Department of Soil Science, Maragheh, \\ Iran. *Corresponding autor: mehdirmti@gmail.com ${ }^{2}$ Sahand University of Technology, Mining Engineering \\ Faculty, Tabriz, Iran. ${ }^{3}$ University of Tabriz, Faculty of Agriculture, Department of Soil Science, Tabriz, Iran. \\ ${ }^{4}$ Monash University, Faculty of Engineering, Department of Civil Engineering, Melbourne, Australia. ${ }^{5}$ \\ University of Tabriz, Faculty of Agriculture, Department of Water Engineering, Tabriz, Iran.
}

\begin{abstract}
Soil moisture determination plays a major role in water and crop management. In this research, the accuracy of the Triangle Method (TM) was evaluated to predict surface soil moisture content using Moderate Resolution Imaging Spectro-radiometer $(M O D I S)$ satellite images with $1 \mathrm{~km}$ resolution. The investigation was carried out within an area of $76 \mathrm{~km}^{2}$ in Lighavn watershed in East Azerbaijan, North West of Iran. The analysis was based on ground measurements of soil moisture at 225 points ( 45 pixels) across the catchment on 2 different days. Ground measurements from the first day were used to train the models, while those from the second day were used for validation. A range of polynomial regressions from $1^{\text {st }}$ to $4^{\text {th }}$ orders were established between the ground measured soil moisture and MODIS Normalized Difference Vegetation Index (NDVI) and Land Surface Temperature $(L S T)$. The best results were obtained for the $4^{\text {th }}$ order polynomial of the $T M$ with the efficiency error $(E R)$ and adjusted determination coefficient $\left(R_{a d j}^{2}\right)$ criterions, respectively, equal to $11.0 \%$ and 0.63 for calibration and $15.9 \%$ and 0.60 for validation stage. Therefore, the $T M$ was found to provide reliable estimates of soil moisture, without the need for prior information of the soil surface roughness or the vegetation type and water content.
\end{abstract}

Keywords: Soil moisture, $N D V I$, land surface temperature, moisture monitoring

\section{Introduction}

Soil moisture is an important parameter for the Soil Water Balance Equation (SWBE) at global, regional, and local scales, including quantification of its components (infiltration, surface runoff, evapotranspiration, and deep percolation), and exchanges in the vadose zone (Davenport et al.
2005). Soil moisture is often referred to as surface soil moisture, meaning the water in upper $10 \mathrm{~cm}$ layer, or root zone soil moisture, meaning the water in the upper 100 to $200 \mathrm{~cm}$ of soil (Wang and Qu 2009). Importantly, soil moisture affects human health and plays an important role in agriculture, economic, 
military, and transportation activities (Serrano 2010). Therefore, sustainable agriculture and water resource management need accurate information of the surface soil moisture. For example, low soil moisture for sustained periods results in drought and plant water deficit, potentially leading to wild fire (Serrano 2010). Conversely, high soil moisture leads to increased risk of flood. Moreover, evaporation rate which is strongly correlated to soil moisture makes a strong connection between land surface and atmosphere (Guo et al. 2005). Therefore, information about the spatial patterns of soil moisture at regional scale can helps to predict storms, the occurrence of frosts and heat waves, and the likelihood of limited vision due to thick fog (Serrano 2010). In addition to traffic-ability of tanks and visibility for jets, soil moisture is important for range of other military applications, e.g. the calculation of density altitude for determining the lift capacity of aircraft ${ }^{1}$.

Direct observations of soil moisture are currently limited to measurements at specific locations. Moreover, such point-based measurements do not represent the spatial distribution of soil moisture, since it is highly variable both spatially and temporally (Engman 1991; Wood et al. 1992). However, technological advances in satellite remote sensing have offered a variety of approaches (Shi et al. 1997, Wen et al. 2003; Das et al. 2008; Van doninck et al. 2011) for measuring soil moisture across a wide area continuously over time. Empirical approaches construct functional relationships between measured variables, while the theoretical ones apply complicated scattering phenomena from probabilistic models of soil, vegetation, and terrain (Ahmad et al. 2010). Remote sensing, consequently, provides an opportunity for routine monitoring of soil moisture

* -http://spectrum.mit.edu/issue/2010-summer/ measuring-moisture/ across large scales (Wang and Qu, 2009) as well as vegetation moisture content (Castro et al. 2014).

Wang and Qu (2009) have classified techniques for the remote sensing of the near-surface soil moisture into 1. visible, 2. thermal infrared, and 3. microwave techniques. Microwave techniques, including radiometer (passive) and radar (active), are currently the preferred approaches for soil moisture remote sensing due to their all-weather capability and stronger relationship with the soil water content. While the more easily interpreted radiometer data is coarse and needs to be downscaled to be used for many of the applications discussed above, the radar data are infrequent through time and are very difficult to interpret, primarily due to need of ancillary surface roughness and vegetation information (Wang and $\mathrm{Qu}$ 2009). Although visible and thermal infrared are affected by clouds, they have fine spatial resolution and can be easier to interpret than radar (Wang and Qu 2009).

The thermal emission has a wavelength region between 3.5 and $14 \mu \mathrm{m}$ (Curran 1985). Remote sensing of the surface soil moisture using optical data relies on either the use of thermal observations alone (Schmugge 1978; Friedl and Davis 1994), or in combination with vegetation indices (Chauhan et al. 2003). The Triangle Method (TM) is categorized as a thermal infrared technique (Wang and Qu 2009), and uses both Land Surface Temperature (LST) and the Normalized Difference Vegetation Index (NDVI) for remote sensing of the surface soil moisture using the Moderate Resolution Imaging Spectro-radiometer (MODIS) satellite images with $1 \mathrm{~km}$ resolution data. The TM was first introduced by Price (1990) and then elaborated upon by others (Carlson et al. 1994; Carlson et al. 1995; Gillies and Carlson 1995; Lambin and Ehrlich 1996; Gillies et al. 1997; Owen et al. 1998; Jiang and Islam 1999, 2001, 2003; Chauhan 
et al. 2003). The $T M$ method has been verified by different investigations (Gillies et al. 1997; Carlson 2007; Wang et al. 2007; Mekonnen 2009) showing a good performance (with $R^{2}$ varying between 0.6 and $1.0)$ to predict soil moisture.

Due to the encouraging results of the recent studies, this paper explores the use of the TM method using $1 \mathrm{~km}$ resolution MODIS data for the unique soil, vegetation, and weather conditions in North Western Iran.

\section{Theoretical background of the method}

The triangle method (Chauhan et al. 2003) is classified as a thermal infrared technique for soil moisture estimation using remotely sensed data (Wang and Qu 2009). It is a stepwise algorithm that is performed according to: 1 . ground measurement of the soil moisture, 2. computation of the NDVI and $L S T$ from satellite images, 3. scaling the computed $N D V I$ and $L S T$ to $N D V I^{*}$ and $L S T^{*}, 4$. constructing polynomials between the measured soil moisture and $N D V I^{*}$ and $L S T^{*}$, and 5. mapping the soil moisture using the derived equations. The $N D V I^{*}$ and $L S T^{*}$ are computed according to:

$$
\begin{aligned}
\mathrm{NDVI}^{*} & =\frac{\mathrm{NDVI}^{-N D V I}{ }_{\text {min }}}{\mathrm{NDVI}_{\text {max }}-\mathrm{NDVI}_{\text {min }}} \\
\mathrm{LST}^{*} & =\frac{\mathrm{LST}^{-\mathrm{LST}_{\text {min }}}}{\mathrm{LST}_{\text {max }}-\mathrm{LST}_{\text {min }}}
\end{aligned}
$$

where $N D V I$ and $L S T$ are the observed values for each pixel, and subscripts max and min imply the maximum and minimum values, respectively. The min and max for the parameters were set to be minimum and maximum for the particular pixel over the season. Carlson et al. (1994) showed that the relationship among soil moisture $(M), N D V I^{*}$, and $L S T^{*}$ is expressed through a regression formula such as:

$$
\mathrm{M}=\sum_{\mathrm{i}=0}^{\mathrm{i}=\mathrm{n}} \sum_{\mathrm{j}=0}^{\mathrm{j}=\mathrm{n}} \mathrm{a}_{\mathrm{ij}} \mathrm{NDVI}^{*(\mathrm{i})} \mathrm{T}^{*(\mathrm{i})}
$$

where $a_{i j}$ is the regression coefficient and the superscripts $i$ and $j$ imply the degree of the polynomials that are chosen for the regression.

\section{Methods and Materials}

\subsection{Study area}

The study was conducted in the Lighvan watershed, East Azerbaijan, located in North Western Iran (Figure 1). The watershed is located at the Sahand Mountain with latitude $37^{\circ} 43^{\prime} 07^{\prime \prime}$ to $37^{\circ} 50^{\prime} 08^{\prime \prime}$ $\mathrm{N}$ and longitude $46^{\circ} 22^{\prime} 23^{\prime \prime}$ to $46^{\circ} 28^{\prime} 05^{\prime \prime} \mathrm{E}$. The Lighvan watershed has an area of 7,854 hectares and an elevation varying from $3,534 \mathrm{~m}$ in the uplands to 2,190m at the watershed outlet (Figure 2), with an average precipitation of $320 \mathrm{~mm}$ per year. Nearly all parts of the study area have coarse textured soils at soil surface $(0-10 \mathrm{~cm})$ consisting of loam, sand, sandy clay loam, sandy loam, and silt loam texture classes (Figure 3-A) (Rahmati, 2014). The major part of the study area consists of bare land (46\%) and poor pasture (42\%) landuses (Figure 3-B) (Rahmati, 2014). Irrigated and dry-land farming covers only $12 \%$ of the area (Rahmati, 2014). 


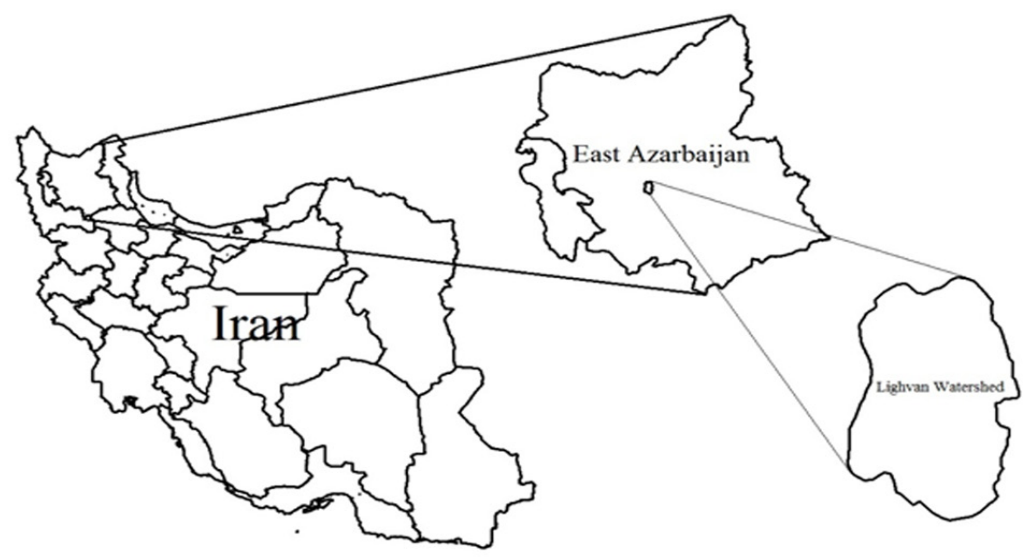

Figure 1. Location of the study area in East Azerbaijan, Iran

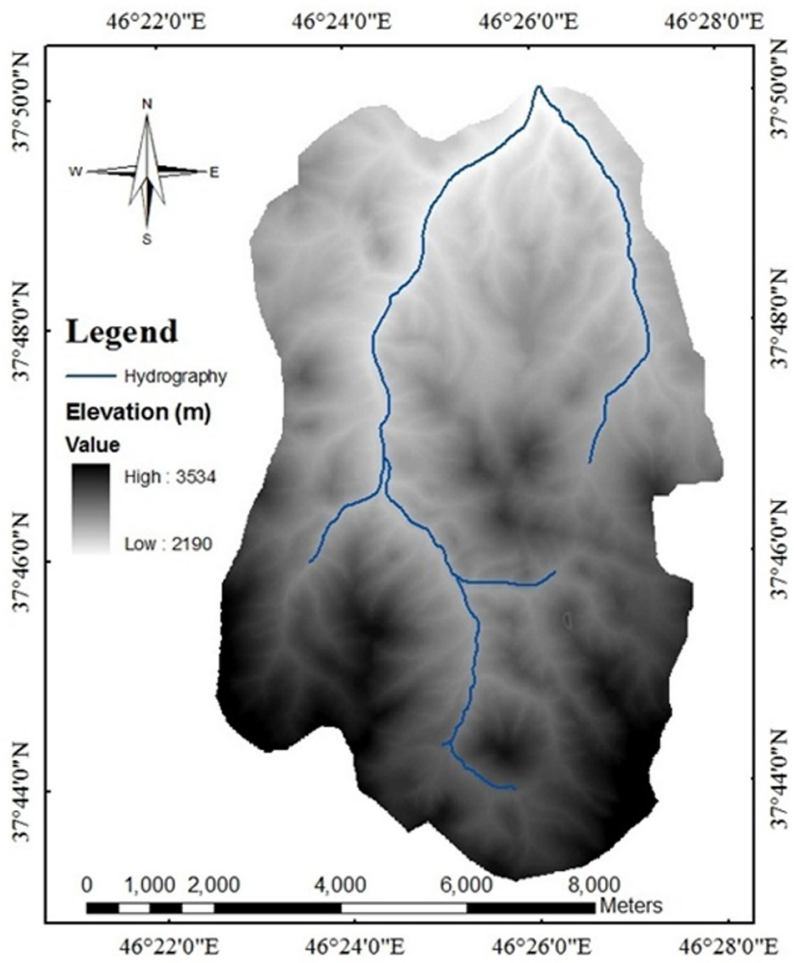

Figure 2. DEM and river network map of the study area 

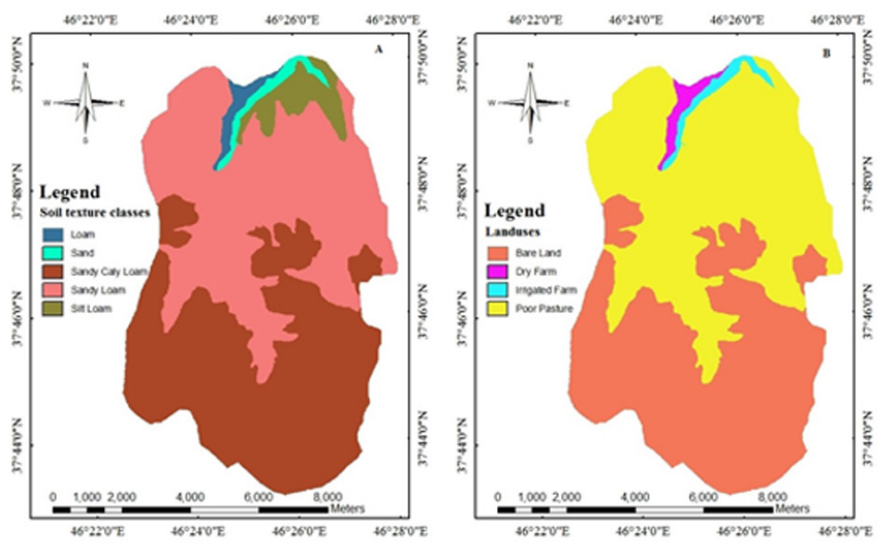

Figure 3. Soil (A) and landuse (B) maps of the study area

\subsection{Field and laboratory experiments}

For sampling purposes, the study area was divided into 1 square kilometer pixels (the same as the MODIS resolution), and soil samples were collected from the 0 to $15 \mathrm{~cm}$ surface layer in each pixel. In total, 225 soil samples were taken from 45 out of 60 complete pixels for volumetric soil moisture determination. In other words, five samples were collected for each pixel and a simple mean was used to combine samples to produce an estimate for each pixel. Figure 4 indicates the location of the sampled pixels and the sampling strategy for each pixel. The Sampling was randomly repeated in two different days (11-June-2012 and 18-June-2012) with the first day's data used to calibrate the polynomials and the second day's data for validation. No rainfall occurred during the period 11-June till 18-June 2012.

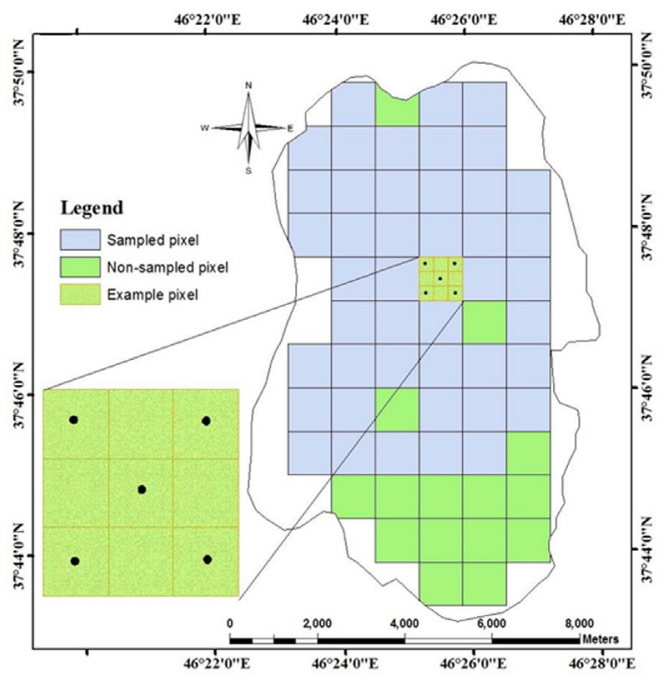

Figure 4. Location of the sampled cells and distribution of sampling points in the study area 
The MODIS sensor is located on the Aqua and Ter$r a$ satellites, having both day and night overpasses. Aqua and Terra products of MODIS were downloaded from the MODIS Adaptive Processing System (MODAPS) through Level 3 and Atmosphere Archive and Distribution System (LAADS) at http://ladsweb. nascom.nasa.gov. MODIS/Terra and its official $L S T$ (MOD11A1) and NDVI (MOD13A2) products were selected for analysis in this investigation, due to being less cloud affected than Aqua (Mekonnen 2009).

Although, the MODIS data of the study area on 11Jun-2012 and 18-Jun-2012 were needed to fulfill this research, the data acquired on 9-Jun-2012 and 15Jun-2012, respectively, were used due to being cloud free. There was no rainfall between days 9 to 11 and 15 to 18 of Jun-2012 to affect soil moisture content significantly.

\subsection{Training and evaluation of the models}

In this research, the $1^{\text {st }}$ to $4^{\text {th }}$ order polynomials were calibrated for their predictive skill in estimating soil moisture by the TM method, using MODIS images as input. The ground measurement of soil moisture was carried out on two different days, being the $11^{\text {th }}$ and $18^{\text {th }}$ June 2012 . The measured data on $11^{\text {th }}$ June were used to calibrate polynomials, while data on $18^{\text {th }}$ June 2012 were used for validation. The MODIS NDVI and LST products of days $9^{\text {th }}$ and $15^{\text {th }}$ June 2012 were used instead of $11^{\text {th }}$ and $18^{\text {th }}$ June 2012, respectively, since the obtained data of $11^{\text {th }}$ and $18^{\text {th }}$ June 2012 were cloud affected. In this case, we assumed that the measured soil moisture on $11^{\text {th }}$ June was correspond for $9^{\text {th }}$ June and those measured on $18^{\text {th }}$ June was correspond for $15^{\text {th }}$ June due to inconsiderable change in soil moisture during one or two days.

\subsection{Terrain correction}

To check terrain effects due to the large elevation difference (around $1200 \mathrm{~m}$ ) from the uplands to the outlet of the catchment, potential temperature $(T)$ was required for elevation correction against $L S T$. Potential temperature is the temperature that a parcel would acquire if adiabatically brought to standard reference pressure $P_{0}$, usually $1013 \mathrm{mb}$ (Mekonnen 2009). Potential temperature can be calculated according to (Mekonnen 2009):

$\mathrm{T}=\operatorname{LST}\left(\frac{P_{0}}{P}\right)^{0.286}$

where $T$ is the potential temperature in $\mathrm{K}, L S T$ is the land surface temperature in $\mathrm{K}, P_{0}$ is the standard reference pressure usually $1013 \mathrm{mb}$, and $P$ is the atmospheric pressure at the surface in $\mathrm{mb}$, computed according to elevation $(Z)$ by:

$$
P=1013\left(\frac{293-0.0065 Z}{293}\right)^{5.26}
$$

where $Z(\mathrm{~km})$ was derived from resampling of the $30 \mathrm{~m}$ resolution DEM into the $1 \mathrm{~km} M O D I S$ resolution using nearest neighbor resampling method. The computed value of $\mathrm{T}$ was then scaled using:

$\mathrm{T}^{*}=\frac{\mathrm{T}-\mathrm{T}_{\min }}{\mathrm{T}_{\max }-\mathrm{T}_{\min }}$

where $T$ is the observed value for each pixel, while subscripts max and min imply the maximum and minimum values, respectively. Finally, polynomials were reconstructed between measured soil moisture and the $N D V I^{*}$ and $T^{*}$ information extracted form MODIS data to check elevation effects on polynomials evaluation. 


\subsection{Performance evaluation}

Determination coefficient $\left(R^{2}\right)$, adjusted determination coefficient $\left(R_{a d j}^{2}\right)$, Root Mean Square Error (RMSE), and evaluating error $(E R)$ criterions were used to evaluate the accuracy of the method for soil moisture prediction. The RMSE and ER criterions were determined by using following equations:

RMSE $=\sqrt{\frac{\sum_{i=1}^{N}\left[M_{i, O b s}-M_{i, S i m}\right]^{2}}{N}}$

$$
\mathrm{ER}=\frac{\mathrm{RMSE}}{\overline{\mathrm{M}_{\mathrm{Obs}}}} \times 100
$$

where $M_{i, S i m}$ and $M_{i, O b s}$ are the simulated and measured soil moisture at point $i, \overline{M_{O b s}}$ is the mean of measured soil moisture, and $N$ is the number of measurements.

\section{Results and Discussion}

Statistics of the ground measured soil moistures for two sampling days are reported in Table 1. There was no rainfall event between two sampling days, with and approximately $0.02 \mathrm{~cm}^{3} \mathrm{~cm}^{-3}$ decrease in soil moisture accordingly. The $N D V I$ and $L S T$ maps of the study area on $9^{\text {th }}$ June are depicted in Figure 5 and their statistical parameters for both sampling days reported in Table 1. According to the Table 1, the day time average of the LST for $9^{\text {th }}$ and $15^{\text {th }}$ June 2012 were 288.11 and $277.63 \mathrm{~K}$, respectively. Table 1 also reports that the average $N D V I$ for sampling days were 0.254 .
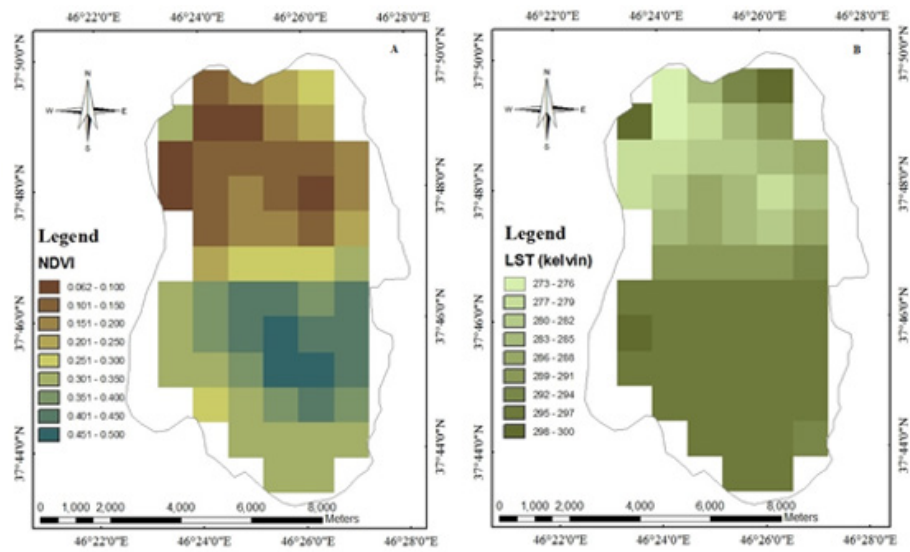

Figure 5. The NDVI (A) and LST (B) maps of the study area on 9-Jun-2012

Table 1. Statistics of ground measured soil moisture (M), and MODIS LST and NDVI of the study area

\begin{tabular}{|c|c|c|c|c|c|c|}
\hline \multirow[b]{2}{*}{ Parameter } & \multicolumn{3}{|c|}{ 9-Jun-2012 } & \multicolumn{3}{|c|}{ 15-Jun-2012 } \\
\hline & $\begin{array}{c}\mathrm{M} \\
\left(\mathrm{cm}^{3} / \mathrm{cm}^{3}\right)\end{array}$ & $\begin{array}{l}\text { LST } \\
\left({ }^{\circ} \mathrm{K}\right)\end{array}$ & NDVI & $\begin{array}{c}\mathrm{M} \\
\left(\mathrm{cm}^{3} / \mathrm{cm}^{3}\right)\end{array}$ & $\begin{array}{l}\text { LST } \\
\left({ }^{\circ} \mathrm{K}\right)\end{array}$ & NDVI \\
\hline Min & 0.124 & 272.66 & 0.062 & 0.100 & 275.15 & 0.062 \\
\hline Max & 0.263 & 299.68 & 0.473 & 0.237 & 284.35 & 0.473 \\
\hline Mean & 0.169 & 288.11 & 0.254 & 0.150 & 277.63 & 0.254 \\
\hline Standard deviation & 0.031 & 7.526 & 0.130 & 0.30 & 2.325 & 0.130 \\
\hline
\end{tabular}




\subsection{Polynomials training and evaluating}

The Data Solver application of the Microsoft Office Excel was used to calibrate the polynomials. The following equation shows the expanded form of Equation. (3) for the $4^{\text {th }}$ order polynomial used in this study:

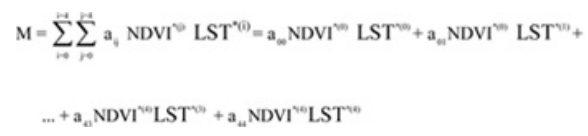

The results of polynomial evaluation for both calibration and validation stages are listed in Table 2 . The outcome showed that an increase in the order of polynomials has resulted in a better prediction of the soil moisture. The $4^{\text {th }}$ and $1^{\text {st }}$ order polynomials possess the highest ( $R M S E=0.019 \mathrm{~cm}^{3} \mathrm{~cm}^{-3}, E R=11 \%$, and $R_{a d j}^{2}=0.63$ ) and lowest $\left(R M S E=0.022 \mathrm{~cm}^{3} \mathrm{~cm}^{-3}, E R=13 \%\right.$, and $R_{a d j}^{2}=0.48$ ) accuracies for the calibration stage, respectively. Each polynomial consists of $(n+1)^{2}$ regression coefficients, in which $\mathrm{n}$ implies the order of the polynomial. So any increase in polynomial order results in a higher number of regression coefficients. Consequently, the higher number of the regression coefficients will require a better training for polynomials. Results of the other investigations (e.g. Carlson 2007 and Mekonnen 2009) show that the higher order the polynomial, the better accuracy of soil moisture prediction, which also consistent with this study. The best performance for the validation stage ( $R M S E=0.024$ $\mathrm{cm}^{3} \mathrm{~cm}^{-3}, E R=15.85 \%$, and $\left.R_{a d j}^{2}=0.60\right)$ was also for the $4^{\text {th }}$ order polynomial. However, results of the $1^{\text {st }}, 2^{\text {nd }}$, and $3^{\text {rd }}$ orders polynomials showed that measured soil moisture had the best correlation with the $3^{\text {rd }}$ order polynomial prediction $\left(R_{a d j}^{2}=0.59\right.$ vs. $R_{a d j}^{2}=0.02$ and $\left.R_{a d j}^{2}=0.37\right)$, while the RMSE and ER criterions had the best agreement with the $2^{\text {nd }}\left(R M S E=0.026 \mathrm{~cm}^{3} \mathrm{~cm}^{-3}\right.$ and $\left.E R=16.96 \%\right)$ and $1^{\text {st }}$ (with $R M S E=0.034 \mathrm{~cm}^{3} \mathrm{~cm}^{-3}$ and $E R=22.53 \%$ ) order polynomials, with the worst results was for the $3^{\text {rd }}$ order polynomial prediction (with $R M S E=0.036 \mathrm{~cm}^{3} \mathrm{~cm}^{-3}$ and $E R=24 \%$ ). Consequently, the $4^{\text {th }}$ order polynomial is proposed for further investigation in the region. The regression coefficients of the $4^{\text {th }}$ order polynomial adopted from the calibration stage are reported in Table 3. The simulated soil moisture maps using the $4^{\text {th }}$ order polynomial are also demonstrated in Figure 6 for both calibration and validation stages. Cross correlation of the measured and simulated soil moistures using the $4^{\text {th }}$ order of polynomial for both calibration and validation stages are depicted in Figure 7, showing a satisfying correlation (calibration $R^{2}=0.840$ and validation $\left.R^{2}=0.829\right)$ with measured data.

Although, the range of the applied data in this research is restricted (one small catchment and 2 sampling days), the results are encouraging. Gillies et al. (1997) estimated soil moisture using TM method and multispectral measurements with standard errors of 16 per cent compared to measured soil moisture. Wang et al. (2007) also executed a $2^{\text {nd }}$ order polynomial of the $T M$ method to estimate soil moisture with a wide range of data (using 93 ground stations data) in eastern China, reporting an $R^{2}$ greater than 0.6 between measured and estimated soil moistures for 82 out of 93 ground stations and greater than 0.7 for 71 out of 93 ground stations. Mekonnen (2009) also applied a $3^{\text {rd }}$ order polynomial of the $T M$ method in northwest Ethiopia using a wide range data from 9 different days of ground measurement, with an $R^{2}$ greater than 0.7 and RMSE of 0.045 .

The key advantages of the TM method, although, are its independence to surface roughness and applicability to pixels with $N D V I>0.4$, which is contrary to others microwave remote sensing techniques (Mekonnen 2009), it is expected that applying a wide range of ground measurement to train the polynomials will result in a better prediction of soil moisture. Carlson (2007) confirmed that the most severe limitation of the $T M$ method is requiring a flat surface and a large number of pixels over an area with a wide range of soil wetness and fractional vegetation cover. 
Table 2. The results of polynomial evaluation for both calibration and validation stages

\begin{tabular}{|c|c|c|c|c|c|c|c|c|}
\hline \multirow{2}{*}{$\begin{array}{c}\text { Order of } \\
\text { polynomial }\end{array}$} & \multicolumn{4}{|c|}{ Training } & \multicolumn{4}{|c|}{ Validation } \\
\hline & $\mathrm{R}^{2}$ & $\mathrm{R}_{\text {adj }}^{2}$ & $\begin{array}{c}\text { RMSE } \\
\left(\mathrm{cm}^{3} \mathrm{~cm}^{-3}\right)\end{array}$ & $\begin{array}{l}\text { ER } \\
(\%)\end{array}$ & $\mathrm{R}^{2}$ & $\mathrm{R}_{\text {adj }}^{2}$ & $\begin{array}{c}\text { RMSE } \\
\left(\mathrm{cm}^{3} \mathrm{~cm}^{-3}\right)\end{array}$ & $\begin{array}{l}\text { ER } \\
(\%)\end{array}$ \\
\hline $1^{\text {st }}$ order & 0.530 & 0.483 & 0.022 & 13.00 & 0.112 & 0.023 & 0.034 & 22.53 \\
\hline $2^{\text {nd }}$ order & 0.637 & 0.544 & 0.021 & 12.22 & 0.501 & 0.373 & 0.026 & 16.96 \\
\hline $3^{\text {rd }}$ order & 0.761 & 0.625 & 0.019 & 11.07 & 0.741 & 0.593 & 0.036 & 24.00 \\
\hline $4^{\text {th }}$ order & 0.840 & 0.630 & 0.019 & 11.00 & 0.829 & 0.604 & 0.024 & 15.85 \\
\hline
\end{tabular}

Table 3. Regression coefficients $\left(a_{i j}\right)$ of the 4 th order polynomial, where $i$ and $j$ imply the power of the NDVI* and LST* in Equation (3), respectively

\begin{tabular}{|c|c|c|c|c|c|c|}
\hline & \multicolumn{5}{|c|}{$\mathrm{i}$} \\
\hline & & 0 & 1 & 2 & 3 & 4 \\
\hline \multirow{5}{*}{$\mathrm{j}$} & 0 & 0.1226 & 0.8685 & -5.1687 & 8.4222 & 0.1450 \\
\hline & 1 & -0.0156 & -0.7725 & 0.0323 & -11.2971 & 1.1789 \\
\hline & 2 & 0.0025 & 8.0978 & -0.0005 & -0.3710 & 0.9904 \\
\hline & 3 & -2.1639 & -2.3652 & 0.4073 & 2.5841 & -0.4100 \\
\hline & 4 & 0.1665 & 0.3341 & 0.0886 & -0.0724 & -0.5460 \\
\hline
\end{tabular}
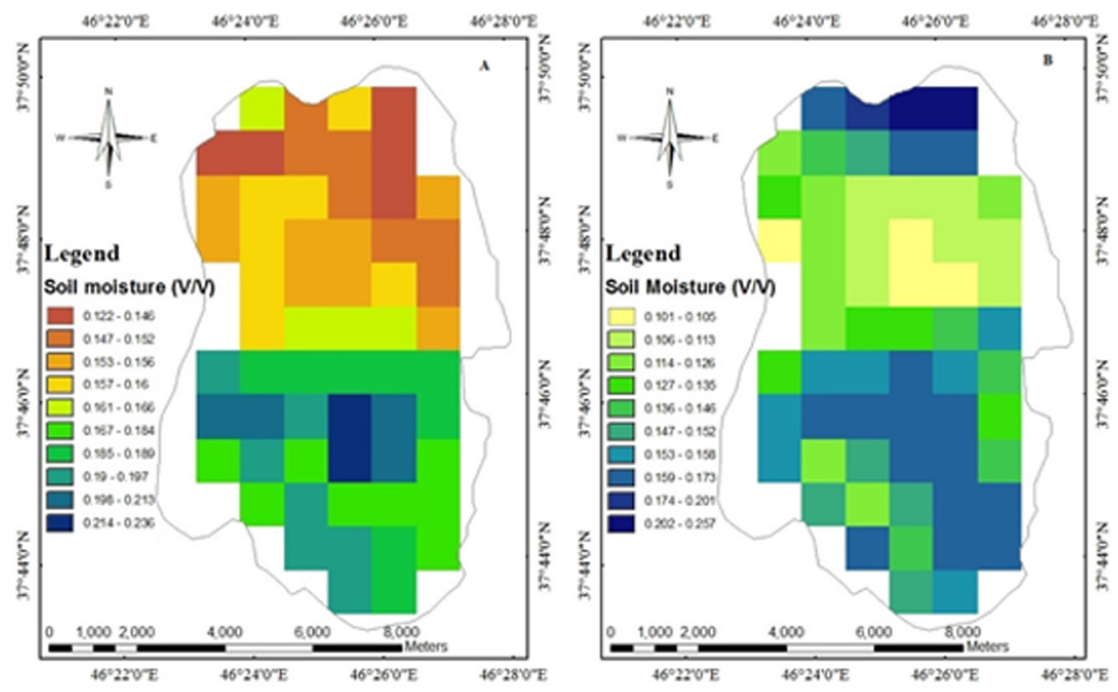

Figure 6. Simulated soil moisture maps by $4^{\text {th }}$ order polynomial for calibration (9-Jun-2012, A) and validation (15-Jun-2012, B) stages 


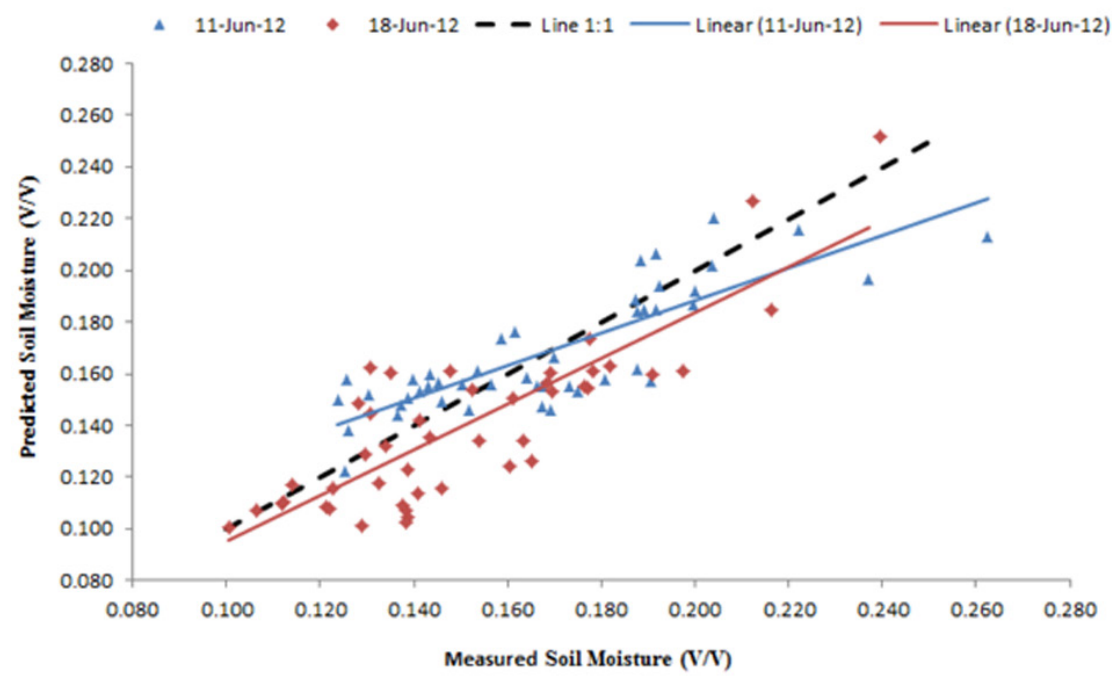

Figure 7. Cross correlation of measured and simulated soil moistures using $4^{\text {th }}$ order polynomial for calibration (9-Jun-2012) and validation (15-Jun-2012) stages

\subsection{Terrain effects evaluation on polynomials}

Since the topography of the study area is irregular and rough, terrain effects on simulated soil moisture were evaluated. Potential surface temperature was used to correct the topographic effects on simulated soil moisture. The evaluation results of constructed polynomials among soil moisture, $N D V I^{*}$, and $T^{*}$ are reported in Table 4 . Although applying potential temperature $\mathrm{T}$ instead of LST resulted in a better validation of $3^{\text {rd }}$ order polynomial
(RMSE of 0.033 vs. $0.036 \mathrm{~cm}^{3} \mathrm{~cm}^{-3}$ and ER of $21.7 v s$. $24.0 \%)$, the other polynomials $\left(1^{\text {st }}, 2^{\text {nd }}\right.$, and $4^{\text {th }}$ orders $)$ showed no sensitivity to the substitution of LST by potential temperature. Contrary to the results of this paper, Mekonnen (2009) showed that the elevation correction resulted in better prediction of the soil moisture. This is possibly due to small size $(\approx 80 \mathrm{~km} 2)$ and reduced elevation variation $(1200 \mathrm{~m})$ of the study area used here in comparison to his study area $(\approx 1768$ km2 and $1900 \mathrm{~m})$.

Table 4. The results of polynomials evaluation after elevation correction on LST using Equation (4)

\begin{tabular}{|c|c|c|c|c|c|c|c|c|}
\hline \multirow{2}{*}{$\begin{array}{c}\text { Order of } \\
\text { polynomial }\end{array}$} & \multicolumn{4}{|c|}{ Training } & \multicolumn{4}{|c|}{ Validation } \\
\hline & $\mathrm{R}^{2}$ & $\mathrm{R}_{\text {adj }}^{2}$ & $\begin{array}{c}\text { RMSE } \\
\left(\mathrm{cm}^{3} \mathrm{~cm}^{-3}\right)\end{array}$ & $\begin{array}{l}\text { ER } \\
(\%)\end{array}$ & $\mathrm{R}^{2}$ & $\mathrm{R}_{\text {adj }}^{2}$ & $\begin{array}{c}\text { RMSE } \\
\left(\mathrm{cm}^{3} \mathrm{~cm}^{-3}\right)\end{array}$ & $\begin{array}{l}\text { ER } \\
(\%)\end{array}$ \\
\hline $1^{\text {st }}$ order & 0.530 & 0.483 & 0.022 & 13.00 & 0.112 & 0.023 & 0.034 & 22.53 \\
\hline $2^{\text {nd }}$ order & 0.637 & 0.544 & 0.021 & 12.22 & 0.501 & 0.373 & 0.026 & 16.95 \\
\hline $3^{\text {rd }}$ order & 0.761 & 0.625 & 0.019 & 11.07 & 0.733 & 0.581 & 0.033 & 21.72 \\
\hline $4^{\text {th }}$ order & 0.840 & 0.630 & 0.019 & 11.00 & 0.829 & 0.605 & 0.024 & 15.86 \\
\hline
\end{tabular}




\section{Conclusion}

The $4^{\text {th }}$ order polynomial of the $T M$ method using MODIS satellite images was shown to predict the soil moisture with $R_{a d j}^{2}=0.63, R M S E=0.019 \mathrm{~cm}^{3} \mathrm{~cm}^{-3}$, and $E R=11 \%$ for calibration; $R_{a d j}^{2}=0.60, R M S E=0.024$ $\mathrm{cm}^{3} \mathrm{~cm}^{-3}$, and $E R=16 \%$ for validation. Applying potential temperature $T$ instead of $L S T$ to correct for the terrain effects on the $T M$ method performance showed no improvement on the method's efficiency. The good results obtained from the current research suggest that the method warrants evaluation at larger scale, with more field sampling data across a wider range of conditions.

\section{References}

Ahmad, S., Kalra, A., Stephen, H. 2010. Estimating soil moisture using remote sensing data: A machine learning approach. Advances in Water Resources. 33, 69-80.

Carlson, T. 2007. An overview of the triangle method for estimating surface evapotranspiration and soil moisture from satellite imagery," Sensors 7, 1612-1629.

Carlson, T.N., Gillies, R.R., Perry, E. 1994. A method to make use of thermal infrared temperature and NDVI measurement to infer surface soil water content and fractional vegetation cover," Remote sensing Reviews. 9, 161-173.

Carlson, T.N., Gillies, R.R., Schmugge, T.J. 1995. An interpretation of methodologies for indirect measurement of soil-water content. Agricultural and Forest Meteorology. 77, 191-205.

Castro, M., Parra, J.C., Morales, L.J., Salas, C. 2014. Establishment of empirical relations between fuel moisture content and the normalized difference vegetation index. Journal of Soil Science and Plant Nutrition. 14 (3), 670-675.
Chauhan, N.S., Miller, S., Ardanuy, P. 2003. Spaceborne soil moisture estimation at high resolution: a microwave-optical/IR synergistic approach. International Journal of Remote Sensing. 24, 4599-4622.

Curran, P.J. 1985. Principles of Remote Sensing. Longman Scientific and Technical, UK, 282.

Das, N.N., Mohanty, B.P., Cosh, M.H., Jackson, T.J. 2008. Modeling and assimilation of root zone soil moisture using remote sensing observations in Walnut Gulch Watershed during SMEX04. Remote Sensing of Environmental. 112, 415-29.

Davenport, I.J., Fernandez-Galvez, J., Gurney, R.J. 2005. A sensitivity analysis of soil moisture retrieval from the Tau-Omega microwave emission model. IEEE Transactions on Geoscience and Remote Sensing. 43, 1304-1316.

Engman, E.T. 1991. Applications of microwave remote sensing of soil moisture for water resources and agriculture. Remote Sensing of Environment. 35, 213-226.

Friedl, M.A., Davis, F.W. 1994. Sources of variation in radiometric surface temperature over a tallgrass prairie. Remote Sensing of Environment. $48,1-17$.

Gillies, R.R., Carlson, T.N. 1995. Thermal Remote Sensing of Surface Soil Water Content with Partial Vegetation Cover for Incorporation into Climate Models. Journal of Applied Meteorology. 34, 745-756.

Gillies, R.R., Carlson, T.N., Cui, J., Kustas, W.P., Humes, K.S. 1997. A verification of the 'triangle' method for obtaining surface soil water content and energy fluxes from remote measurements of the Normalized Difference Vegetation Index (NDVI) and surface radiant temperature. International Journal of Remote Sensing. 18, 3145-3166. 
Guo, Z., Dirmeyer, P.A., Koster, R.D. et al. 2005. GLACE: the global land-atmosphere coupling experiment. Part II: analysis. American Meteorological Society. 7, 611-625.

Jiang, L., Islam, S. 1999. A methodology for estimation of surface evapotranspiration over large areas using remote sensing observations. Geophysical Research Letters. 26, 2773-2776.

Jiang, L., Islam, S. 2001. Estimation of surface evaporation map over southern Great Plains using remote sensing data. Water Resources Research. 37, 329-340.

Jiang, L., Islam, S. 2003. An Inter-comparison of Regional Latent Heat Flux Estimation using Remote Sensing Data. International Journal of Remote Sensing. 24, 2221-2236.

Lambin, E.G., Ehrlich, D. 1996. The Surface Temperature-vegetation Index Space for Land Cover and Land-cover Change Analysis. International Journal of Remote Sensing. 17, 463 487.

Mekonnen, D.F. 2009. Satellite remote sensing for soil moisture estimation: Gumara catchment, Ethiopia. Master Science Thesis, International Institute for Geo-information Science and Earth observation, The Netherland.

Owen, T.W., Carlson, T.N., Gillies, R.R. 1998. An assessment of satellite remotely-sensed land cover parameters in quantitatively describing the climatic effect of urbanization. International Journal of Remote Sensing. 19, 1663-1681.

Price, J.C. 1990. Using spatial context in satellite data to infer regional scale evapotranspiration. IEEE Transactions on Geoscience and Remote Sensing. 28, 940-948.

Rahmati, M. 2014. Estimating soil infiltration rate by remote sensing and its using in LISEM model for Lighvan watershed erosion prediction. Thesis for $\mathrm{PhD}$, University of Tabriz, Tabriz, Iran.
Schmugge, T.J. 1978. Remote sensing of surface soil moisture. Journal of Applied Meteorology. 17, 1549-1557.

Serrano, M.H.L.R. 2010. Satellite Remote Sensing of Soil Moisture. Master Science Thesis, Department of Meteorology, University of Reading, England.

Shi, J., Wang, A., Hsu, Y., O’Neill, P.E., Engman, E.T. 1997. Estimation of bare surface soil moisture and surface roughness parameter using L-band SAR image data. IEEE Transactions on Geoscience and Remote Sensing. 35, 1254-66.

Van doninck, J., Peters, J., De Baets, B., De Clercq, E.M., Ducheyne, E., Verhoest, N.E.C. 2011. The potential of multitemporal Aqua and Terra MODIS apparent thermal inertia as a soil moisture indicator. International Journal of Applied Earth Observation and Geoinformation. 13, 934-941.

Wang, L., Qu, J.J. 2009. Satellite remote sensing applications for surface soil moisture monitoring: A review. Frontiers of Earth Science in China. 3, 237-247.

Wang, L., Qu, J. J., Zhang, S., Hao, X., Dasgupta, S. 2007. Soil moisture estmiation using MODIS and ground measurments in eastern China. International Journal of Remote Sensing. 28, 1413-1418.

Wen, J., Su, Z., Ma, Y. 2003. Determination of land surface temperature and soil moisture from tropical rainfall measuring mission/microwave imager remote sensing data. Journal of Geophysical Research. 108, 805-26.

Wood, E.F., Lettenmaier, D.P., Zartarian, V.G. 1992. A land-surface hydrology parameterization with subgrid variability for general circulation models. Journal of Geophysical Research. 97, 2717-2728. 